\title{
Modulation of transforming growth factor- $\beta$ signaling transducers in colon adenocarcinoma cells induced by staphylococcal enterotoxin B
}

ABOLFAZL AKBARI ${ }^{1}$, GHOLAM REZA MOBINI ${ }^{2}$, REZA MAGHSOUDI $^{3}$, JAVAD AKHTARI $^{4}$, EBRAHIM FAGHIHLOO ${ }^{5}$ and ZOHREH FARAHNEJAD ${ }^{6,7}$

${ }^{1}$ Colorectal Research Center, Iran University of Medical Sciences, Tehran 1313114456;

${ }^{2}$ Medical Plants Research Center; ${ }^{3}$ Department of Microbiology and Immunology,

Shahrekord University of Medical Sciences, Shahrekord 8815713471; ${ }^{4}$ Immunogenetic Research Center,

Faculty of Medicine, Mazandaran University of Medical Sciences, Sari $48175866 ;{ }^{5}$ Department of Virology,

School of Public Health, Tehran University of Medical Sciences, Tehran 1313114456; ${ }^{6}$ Department of Medical Mycology,

AJA University of Medical Sciences; ${ }^{7}$ Department of Microbiology, Infectious Diseases Research Center,

AJA University of Medical Sciences, Tehran 1917793164, Iran

Received November 5, 2014; Accepted September 9, 2015

DOI: $10.3892 / \mathrm{mmr} .2015 .4596$

\begin{abstract}
Colorectal cancer (CRC) is a notable cause of cancer-associated mortality worldwide, making it a pertinent topic for the study of cancer and its treatment. Staphylococcal enterotoxin B (SEB), an enterotoxin produced by Staphylococcus aureus, has been demonstrated to exert anticancer and antimetastatic effects due to its ability to modify cell immunity and cellular signaling pathways. In the current study, SEB was investigated, including whether it exerts its growth inhibitory effects on colon adenocarcinoma cells. This may occur through the manipulation of a key tumor growth factor, termed transforming growth factor- $\beta$ (TGF- $\beta$ ), and its signaling pathway transducer, Smad2/3. The human colon adenocarcinoma HCT116 cell line was treated with different concentrations of SEB, and cell number was measured using MTT assay at different treatment times. Smad2/3 RNA expression level was analyzed in untreated or SEB-treated cells using quantitative polymerase chain reaction, which indicated significant differences between cell viability and Smad2/3 expression levels. SEB effectively downregulated Smad2/3 expression in the HCT116 cells at concentrations
\end{abstract}

Correspondence to: Dr Zohreh Farahnejad, Department of Medical Mycology, AJA University of Medical Sciences, West Fatemi Avenue, Tehran 1917793164, Iran

E-mail: zfarahnejad@yahoo.com

Abbreviations: TGF- $\beta$, transforming growth factor- $\beta$; CRC, colorectal cancer; SEB, staphylococcal enterotoxin B

Key words: colorectal cancer, staphylococcal enterotoxin B, transforming growth factor- $\beta$, signal transducers, Smad $2 / 3$ of 1 and $2 \mu \mathrm{g} / \mathrm{ml}(\mathrm{P}=0.0021$ and $\mathrm{P}=0.0017$, respectively). SEB concentrations that were effective at inhibiting Smad2/3 expression were correlated with those able to inhibit the proliferation of the cancer cells. SEB inhibited Smad2/3 expression at the mRNA level in a concentration- and time-dependent manner. The present study thus proposed SEB as an agent able to significantly reduce $\mathrm{Smad} / 3$ expression in colon cancer cells, provoking moderate TGF- $\beta$ growth signaling and the reduction of tumor cell proliferation.

\section{Introduction}

Colorectal cancer (CRC) is the second leading cause of cancer-associated mortality worldwide, according to the International Agency for Research on Cancer (1). Cancer reports reveal that $\sim 1$ million new cases of CRC were detected worldwide in 2008, establishing it as a key focus for the study of cancer and therapeutic approaches $(1,2)$. In CRC and numerous other types of cancer, it has been established that the aberration of the growth factor signaling pathways can function in tumor initiation, progression and metastasis (3-6). Transforming growth factor $\beta$ (TGF- $\beta$ ) has been identified as a key growth factor triggering varied biological processes, including proliferation, differentiation and programmed cell death (apoptosis). Studies indicate that this factor functions in signaling during the later stages of certain types of cancer and promotes tumor development, progression and metastasis $(7,8)$.

TGF- $\beta$ binds heterodimeric receptor complexes of transmembrane serine/threonine kinases known as type I and type II receptors (TG $\beta$ RI and TG $\beta$ RII). Cell signaling triggers interaction of TGF- $\beta$ with TG $\beta$ RII, followed by TG $\beta R$ I activation. Activated TG $\beta$ RI initiates the recruitment and phosphorylation of a family of signal transducers, termed Smad factors. A complex of phosphorylated Smad2 
and Smad3 components associates with Smad4, and these translocate to the nucleus to activate the transcription of downstream target genes (7-9).

It is well-established that growth factors with a broad range of cellular effects, such as TGF- $\beta$, must be subject to extensive regulation to control their expression and function. This regulation includes mechanisms that occur during a diversity of growth events that are dependent on cell and tissue contexts; it may be apt, therefore, to utilize cell growth inhibition as a form of cancer therapy $(8,9)$. Several reports have indicated that the targeting of TGF- $\beta$ signaling during the late stages of carcinogenesis may be a useful tool for the treatment of human cancer, including CRC, glioblastoma and breast cancer; repressing the function of the TGF- $\beta$ signal transduction pathway components may thus provide an effective therapeutic strategy for the treatment of CRC $(9,10)$.

For hundreds of years, it has been reported that certain infectious diseases exert a beneficial, therapeutic effect upon malignancy (11-13). Bacteria and associated molecules have been utilized in diverse fields of cancer therapy, including their use as vectors for gene therapy, as carriers of tumoricidal agents and bacterial toxins have been used in tumor repression within their role of binding tumor surface antigens. Toxins are unique bacterial factors with a suggested protective role in carcinogenesis and in cancer remission (14-17). Previous studies have demonstrated that bacterial toxins may lead to the cytolysis and death of a range of malignant cells; in this regard, the bacterial toxin-based vaccine was widely used to successfully treat sarcomas, carcinomas, lymphomas, melanomas and myelomas $(13,14)$. There is evidence that certain types of bacterial toxins may aid the prevention or treatment of cancer; it is this that inspired the development of the earliest toxin-based cancer therapies (11-13).

Certain bacteria secrete enterotoxins able to modulate cellular signaling processes, controlling proliferation, apoptosis and differentiation during carcinogenesis (18-21). Although it has demonstrated successful results in vivo, further investigation into the targeting mechanisms of bacteria is required in order to develop a complete therapeutic approach for cancer treatment. Regarding the basic function of bacterial enterotoxins in tumor repression, it is rational to hypothesize that anticancer properties may partially be associated with their regulation of the cell signaling genes involved in cancer development and progression. However, modulation of a distinct signaling pathway to explain the possible inhibitory action of staphylococcal enterotoxins in cancer, including $\mathrm{CRC}$, has yet to be elucidated.

Staphylococcal enterotoxins are a family of structurally-related proteins produced by Staphylococcus aureus. Staphylococcal enterotoxin B (SEB) belongs to the superantigen protein family. These are proteins or peptides produced by various microorganisms, including bacteria, mycoplasma or viruses, and induce T lymphocytes clonally (22-24). It has been demonstrated that SEB exerts anticancer and antimetastatic effects due to its ability to modify cell immunity processes and cancer cell signaling pathways $(22,23)$. These promising characteristics prompted study into whether SEB reduces CRC cell proliferation. As bacterial enterotoxins have, to a certain extent, previously been harnessed for cancer treatment (22-24), we hypothesized that the anticancer properties of the enterotoxin may be partially recapitulated by manipulating growth signaling pathways.

The aim of the present study was to investigate the growth inhibitory effect of SEB on CRC growth through the in vitro manipulation of the TGF- $\beta$ signaling pathway transduction components Smad2/3, in vitro. The study was designed to provide an insight into the molecular mechanism of SEB in colon cancer cell signaling pathways, emphasizing the potential for novel toxin-based cancer therapies.

\section{Materials and methods}

Cell culture. HCT116, a human colorectal adenocarcinoma cell line from original tumors of pathological differentiation grade II, was selected from a panel of CRC cell lines to examine the downstream effects of SEB on TGF- $\beta$.

The cell line was obtained from the National Cell Bank of Iran, affiliated to the Pasteur Institute (Tehran, Iran). The cells were grown in RPMI-1640 medium containing $25 \mathrm{mM}$ D-glucose, $4 \mathrm{mM}$ L-glutamine and $1 \mathrm{mM}$ sodium pyruvate, supplemented with $5 \%$ (v/v) heat-inactivated fetal bovine serum (FBS), $2 \mathrm{mM}$ GlutaMAX, $100 \mathrm{U} / \mathrm{ml}$ penicillin, $100 \mu \mathrm{g} / \mathrm{ml}$ streptomycin and $250 \mathrm{ng} / \mathrm{ml}$ amphotericin (all Gibco; Thermo Fisher Scientific, Darmstadt, Germany) in $25-\mathrm{cm}^{2}$ culture flasks (SPL Life Sciences, Pocheon, Korea). The cells were maintained at $37^{\circ} \mathrm{C}$ in a humidified, $95 \%$ air $/ 5 \% \mathrm{CO}_{2}$ atmosphere incubator in steady-state conditions. Cell viability was assessed using a trypan blue (Sigma-Aldrich, St. Louis, MO, USA) exclusion test and routinely demonstrated $>95 \%$ viable cells in all flasks.

SEB preparation. SEB (Sigma-Aldrich) was dissolved in distilled water according to the manufacturer's protocols. The enterotoxin was prepared as stock solutions of $20 \mu \mathrm{g} / \mathrm{ml}$ and stored at $-20^{\circ} \mathrm{C}$ until use.

MTT assay. To quantify cell proliferation, the in vitro growth inhibitory effect of SEB following incubation for 24, 48 or $72 \mathrm{~h}$ was measured using an MTT assay (Roche Applied Science, Mannheim, Germany). Monolayer cultures were trypsinized in the exponential growth phase and viable cell counts were assessed using trypan blue exclusion assay. The cells were then seeded in 96-well flat-bottom microtitration plates (SPL Life Sciences) at a density of $10^{5}$ cells/well (200 $\mu 1$ media/well). After $24 \mathrm{~h}$, upon reaching $\sim 85 \%$ confluence, the cells were treated with different concentrations of SEB $(0.5,1$ and $2 \mu \mathrm{g} / \mathrm{ml})$. In all in vitro experiments, untreated and distilled water-treated cells were used as controls (with a final volume of $5 \mu \mathrm{l})$.

Following $24 \mathrm{~h}$ of drug application, for the recovery period, the cells were washed twice with fresh, FBS-free medium and the culture was continued (Fig. 1). This medium was then replaced with FBS-containing medium to remove unbound SEB.

Complete medium was replaced with $100 \mu \mathrm{l}$ MTT after 24, 48 and $72 \mathrm{~h}$ of treatment. The cells were incubated for $3 \mathrm{~h}$ at $37^{\circ} \mathrm{C}$, and then $100 \mu \mathrm{l}$ dimethyl sulfoxide was added to each well. The optical density (OD) was measured at a wavelength of $570 \mathrm{~nm}$ with background subtraction at $630 \mathrm{~nm}$ using an ELX808 spectrophotometric microplate 
reader (BioTek Instruments, Inc., Winooski, VT, USA). Cell viability was calculated using the following formula: Cell viability $(\%)=(\mathrm{OD}$ drug exposure $/ \mathrm{OD}$ control $) \times 100$.

Total RNA extraction from cells. Total RNA was extracted from the cultured HCT116 cells prior to or subsequent to 24, 48 and $72 \mathrm{~h}$ of treatment with SEB. Total cellular RNA was extracted using TRIzol reagent (Invitrogen; Thermo Fisher Scientific, Karlsruhe, Germany) according to the manufacturer's protocols. Extracted total RNA was stored at $-70^{\circ} \mathrm{C}$ until use.

Gene expression analysis by reverse-transcription quantitative polymerase chain reaction ( $R T-q P C R)$. Smad2/3 gene expression level was analyzed by qPCR using the SYBR-Green method, with specific forward and reverse primers used to amplify the relevant genes (Table I) supplied by Genfanavaran (Tehran, Iran). GAPDH primers were used as an endogenous, positive control, and the data were normalized to the expression level of this housekeeping gene. This method included two steps as follows: i) RT-qPCR. RNA was transcribed to complementary DNA (cDNA) using the oligo(dT) procedure. Briefly, the cDNA was synthesized using total RNA and specific primers in a reverse transcription reaction. This reaction was performed in a volume of $10 \mu \mathrm{l}$ containing $1 \mu \mathrm{l}$ total RNA, $1 \mu 10.5 \mathrm{mM}$ oligo(dT) RT primer, $1 \mu 110 \mathrm{mM}$ dNTP, $1 \mu \mathrm{l}$ reverse transcriptase and $6 \mu 1$ reaction buffer. The reaction was incubated at $42^{\circ} \mathrm{C}$ for $60 \mathrm{~min}$, then terminated by heating at $85^{\circ} \mathrm{C}$ for $5 \mathrm{~min}$.

Subsequently, diluted cDNAs were amplified in a 20- $\mu 1$ reaction containing SYBR-Green Master mix (Takara, Kyoto, Japan), forward and reverse Smad2/3-specific primers (each $1 \mu \mathrm{l})$ and diethylpyrocarbonate-treated distilled water, using 35 cycles of PCR amplification under the following conditions: Denaturing at $95^{\circ} \mathrm{C}$ for $1 \mathrm{~min}$, annealing at $56^{\circ} \mathrm{C}$ for $1 \mathrm{~min}$ and extension at $72^{\circ} \mathrm{C}$ for $1 \mathrm{~min}$. The PCR was performed on a CFX96 Touch Real-Time PCR Detection system (Bio-Rad Laboratories, Inc., Hercules, CA, USA).

All reactions were performed in triplicate. Specificity of primers was verified by observing a single peak dissociation curve for each run. The quantification cycle $(\mathrm{Cq})$ was defined as the fractional cycle number at which the fluorescence passes the fixed threshold. Cq values were converted into total copy numbers using a standard curve. The absence of contamination was verified using distilled water as non-template controls. PCR products were visualized by electrophoresis on a $2 \%$ agarose gel in TAE buffer using GelRed (Biotium, Inc., Hayward, CA, USA) (Fig. 2).

Statistical analysis. PCR data analysis was performed using the $2^{-\Delta \Delta c q}$ method via GraphPad Prism 5.0 software (GraphPad Software, Inc., La Jolla, CA, USA). The mean, standard deviation, standard error of the mean and ranges of each parameter were calculated. A comparison was made of the mean and variance of gene expression using an analysis of variance (ANOVA). Significant differences were also determined (Prism) using ANOVA and Tukey's post-hoc test, or the unpaired Student's t-test, when applicable. $\mathrm{P}<0.05$ was considered to indicate a statistically significant difference between data sets.
Table I. Primer sequences used for quantitative polymerase chain reaction in the present study.

\begin{tabular}{|c|c|c|}
\hline $\begin{array}{l}\text { Target } \\
\text { gene }\end{array}$ & Primer sequence & $\begin{array}{l}\text { Product } \\
\text { size, bp }\end{array}$ \\
\hline Smad2 & & 480 \\
\hline Forward & $\begin{array}{l}\text { 5'-TCAAGCTTGAGTGTAAAC } \\
\text { CCTTACCACTATC-3' }\end{array}$ & \\
\hline Reverse & $\begin{array}{l}\text { 5'-TAGCGGCCGCGAAAGCTA } \\
\text { TGATTAACAG48GGG-3' }\end{array}$ & \\
\hline Smad3 & & 340 \\
\hline Forward & $\begin{array}{l}\text { 5'-TCAAGCTTGAACACCAGT } \\
\text { TCTACCTCCTG-3' }\end{array}$ & \\
\hline Reverse & $\begin{array}{l}\text { 5'-TAGCGGCCGCGAAATGTC } \\
\text { TCCCCGACGCGCTG-3 }\end{array}$ & \\
\hline GAPDH & & 190 \\
\hline Forward & $\begin{array}{l}\text { 5'-CGTTCCCAAAGTCCTCCT } \\
\text { GTTTC-3' }\end{array}$ & \\
\hline Reverse & $\begin{array}{l}\text { 5'-TTTTTTTCCGCAGCCGCC } \\
\text { TG-3' }\end{array}$ & \\
\hline
\end{tabular}

\section{Results}

SEB reduces the growth of the colon adenocarcinoma HCT116 cell line. In order to test SEB antiproliferative activities, an MTT assay was used to evaluate the cell growth inhibitory effect upon altering duration and concentration of treatment. The results indicated that 1 and $2 \mu \mathrm{g} / \mathrm{ml} \mathrm{SEB}$ significantly decreased HCT116 cell viability after $48 \mathrm{~h}$ of treatment ( $\mathrm{P}=0.0021$ and $\mathrm{P}=0.0017$, respectively). It was concluded that SEB exerts its growth inhibitory effects in a concentration- and time-dependent manner. Overall, the data demonstrated that SEB was an effective inhibitor of human colon cancer cell proliferation (Fig. 3).

SEB downregulates Smad2/3 expression. The expression levels of TGF- $\beta$ signaling targets Smad 2 and -3 were evaluated by qPCR. The results revealed that 1 and $2 \mu \mathrm{g} / \mathrm{ml}$ of SEB reduced $\mathrm{Smad} 2 / 3$ expression in the human colon adenocarcinoma HCT116 cell line. SEB treatment at $2 \mu \mathrm{g} / \mathrm{ml}$ for $72 \mathrm{~h}$ significantly reduced Smad 2 expression $(\mathrm{P}=0.006)$, while Smad3 expression was significantly reduced by SEB treatment at concentrations of $2 \mu \mathrm{g} / \mathrm{ml}$ for $48 \mathrm{~h}(\mathrm{P}=0.0075)$, and at 1 and $2 \mu \mathrm{g} / \mathrm{ml}$ for $72 \mathrm{~h}(\mathrm{P}=0.011$ and $\mathrm{P}=0.004$, respectively). SEB reduced Smad2/3 expression in a dose- and time-dependent manner (Fig. 4). SEB inhibited the growth of HCT116 cells at high concentrations, which may be a partial consequence of the downregulation of TGF- $\beta$ signaling pathway components.

It was predicted that SEB, as a potent inhibitor of colon cancer cell proliferation, would regulate the expression of key transducer genes controlling TGF- $\beta$ cancer cell signaling. The SEB concentrations effective at inhibiting Smad $2 / 3$ expression were correlated with those used to inhibit the proliferation of the HCT116 cells.

According to the data presented in the current study, Smad $2 / 3$ downregulation in the presence of SEB may precede 

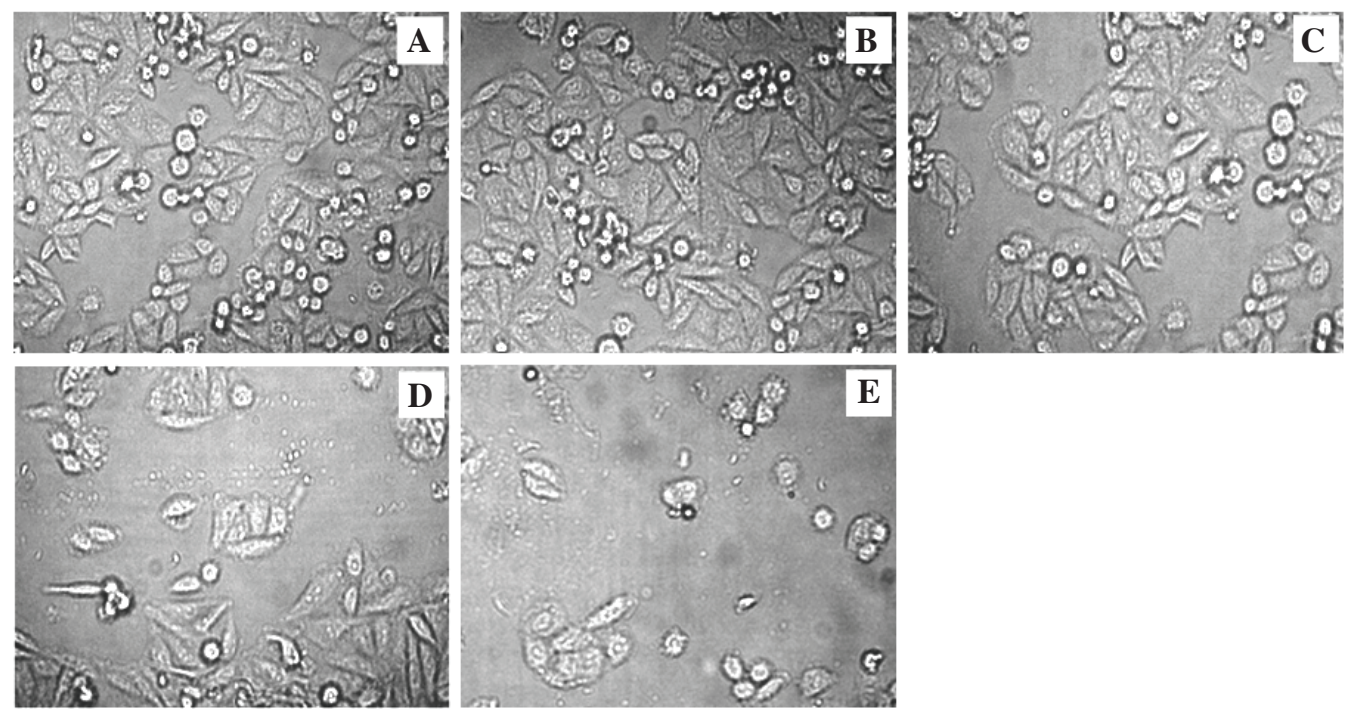

Figure 1. HCT116 cell culture and treatment with SEB. HCT116 cells were cultured and treated with (A) 0.5 , (B) 1 or (C) $2 \mu \mathrm{g} / \mathrm{ml}$ concentrations of SEB (D) Untreated and (E) distilled water-treated cells were used as controls The cells were cultured as a monolayer in microtitration plates and cell morphology was evaluated microscopically after $48 \mathrm{~h}$ of SEB exposure (magnification, x400). SEB, staphylococcal enterotoxin B.

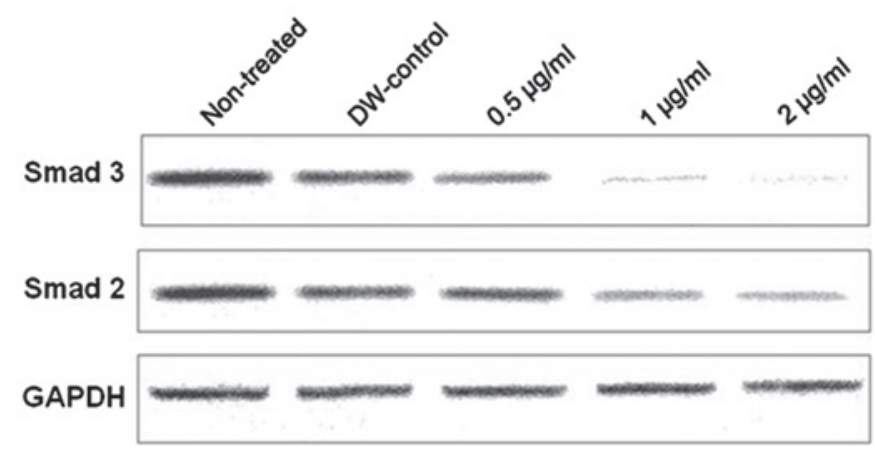

Figure 2. Gel electrophoresis of polymerase chain reaction (PCR) products. Smad 2, Smad 3 and GAPDH (positive control) PCR products were visualized by agarose gel electrophoresis, via GelRed fluorescence. DW, distilled water.

the inhibitory effects of SEB on proliferation; however, this proposal requires further empirical evaluation prior to trial as a CRC therapy.

\section{Discussion}

Malignancies such as CRC are currently considered an important area of study, due to the burden of the disease and the mortality rate (2-5). In numerous types of cancer, it has been established that aberration in genes encoding TGF- $\beta$ signaling components can contribute to colon carcinogenesis in humans $(7,8)$. This signaling pathway controls numerous cellular functions, including epithelial cell proliferation, apoptosis and migration, in addition to tumor initiation, progression and metastasis $(8,9)$, making it a suitable target for cancer therapy $(9,10)$.

Bacterial toxins are widely studied for their anticancer activities and certain examples are currently in clinical development, inciting anticipation for their pharmacological use in cancer treatment (15-17). These toxins can function to kill cells or alter cellular processes controlling proliferation, apoptosis
A

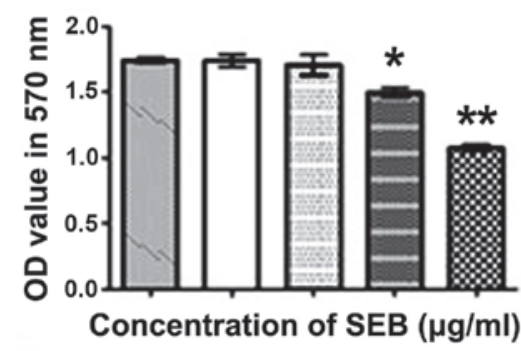

B
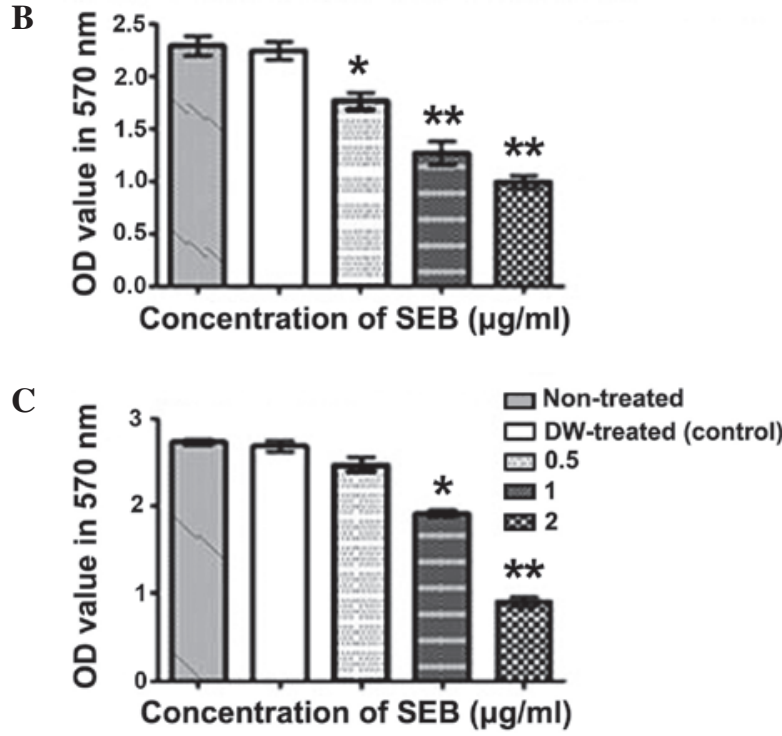

Figure 3. Cell viability of HCT116 after (A) 24, (B) 48 and (C) $72 \mathrm{~h}$ of SEB treatment. MTT assay results demonstrated that the duration of SEB treatment significantly inhibited the growth of the HCT116 cells at concentrations of 1 and $2 \mu \mathrm{g} / \mathrm{ml}$. ${ }^{* * * *} \mathrm{P}<0.05$. SEB, staphylococcal enterotoxin B; DW, distilled water.

and differentiation in carcinogenesis, and these salient roles have stimulated study into whether these may be useful anticancer agents $(14,15,17)$. Despite successful results in vivo, further investigation into the targeting mechanisms used 
A

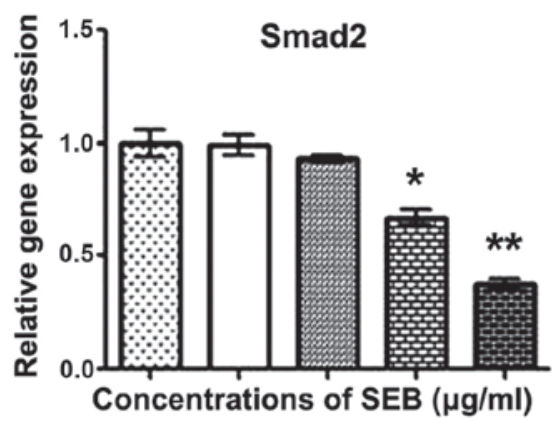

B

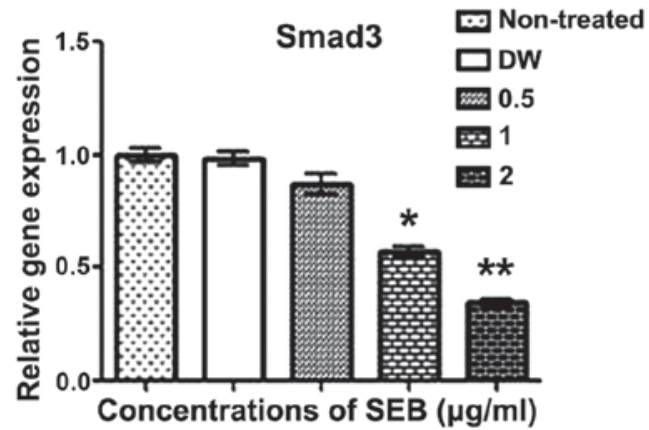

Figure 4. SEB downregulates Smad2 and Smad3 expression Relative (A) Smad2 and (B) Smad3 gene expression, normalized against GAPDH levels. The HCT116 cells showed significantly reduced Smad2 and Smad3 expression after $48 \mathrm{~h}$ of treatment with 1 and $2 \mu \mathrm{g} / \mathrm{ml}$ of SEB. ${ }^{*}{ }^{* *} \mathrm{P}<0.05$. SEB, staphylococcal enterotoxin B; DW, distilled water.

by bacteria are required to generate a complete therapeutic approach in cancer treatment. In several studies, however, the cancer-promoting signaling pathways instigated by bacterial toxins have been evaluated (19-21).

SEB belongs to the family of superantigens. These proteins bind the $\beta$-chain of the T cell receptor and the major histocompatibility complex class II dimer $(22,23)$. It has been suggested that SEB exerts anticancer and antimetastatic advantages via the modification of cancer signaling pathways and cell immunity (24). We therefore hypothesized that the anticancer functions of the enterotoxin may be partially due to changes to cancer signaling pathways.

$\mathrm{SEB}$, the potent inhibitor of colon cancer cell proliferation analyzed in the current study, was predicted to modulate the expression of key transducer genes controlling TGF- $\beta$ cancer cell signaling. The present study aimed to provide an insight into this molecular mechanism, with an overall objective of promoting toxin use in CRC therapy and, potentially, other malignancies involving TGF- $\beta$ signaling.

As previous studies implicated functionally active SEB-binding structures in mediating target cell killing in a range of human colon carcinoma cells (25), HCT116 cells were thus selected as a promising CRC model in the present study. It has also previously been demonstrated that these receptors are distinct from the conventional MHC class II molecules and bind to SEB in a class II-independent manner (25).

Treatment of HCT116 cells at different concentrations for varying durations indicated that SEB treatment resulted in the time- and concentration-dependent inhibition of Smad2/3 expression. The SEB inhibitory action upon Smad2/3 expression occurred at concentrations as low as $1 \mu \mathrm{g} / \mathrm{ml}$. It was presumed that this observable phenomenon resulted from the downregulated expression of TGF- $\beta$ signaling components. SEB was more effective at reducing Smad3 expression than Smad2 expression (Fig. 2) and SEB was also demonstrated to exert an inhibitory effect on HCT116 cell proliferation subsequent to $48 \mathrm{~h}$ treatment at concentrations of 1 and $2 \mu \mathrm{g} / \mathrm{ml}$ $(\mathrm{P}=0.0021$ and $\mathrm{P}=0.0017$, respectively). The SEB concentrations effective at inhibiting Smad2/3 expression correlated with those able to inhibit HCT116 cell proliferation. According to the data presented in the current study, it was hypothesized that Smad2/3 downregulation may precede the SEB inhibition of cell proliferation, but further evaluation is required to confirm this.

Results of the present study are consistent with those from previous studies, indicating that SEB exerts anti-angiogenic effects (22-24). In these studies, SEB was demonstrated to be effective at inducing apoptosis and attenuating cancer cell proliferation.

In accordance with the present study, a previous study revealed that SEB induced the Fas/Fas ligand-mediated cytolysis of target cells (26), postulating that Fas/Fas ligand may be a key mediator for SEB-mediated cell death (26). In this regard, it should be noted that TGF- $\beta$ also activates other downstream signaling pathways, including Rho GTPases, the extracellular signaling-regulated kinases, c-Jun NH2-terminals kinase and phosphatidylinositol-3 kinase (8-10), and it is probable that these pathways are also affected by enterotoxin activity. The use of SEB in the complete reduction of CRC proliferation, acting solely through Smad2/3 downregulation, therefore requires comprehensive examination.

Additionally, it has previously been reported that anthrax toxin (a dangerous bacterial toxin secreted by Bacillus anthracis) inhibits the growth of Ras-transformed cancerous cells by disturbing mitogen-activated protein kinase (MAPK) signaling pathways. It has therefore been suggested that this toxin may also be used against cancer cells in which MAPKs are activated by oncogenic proteins; this specificity ensures the selective damage of tumors at a low dosage (27). Furthermore, bacterial toxins may be used in targeted cancer therapy or synergistically potentiate the activity of anticancer drugs (28-30). It is therefore recommended that additional studies further analyze the synergistic activity of enterotoxin with anticancer drugs.

Although SEB is proposed to be an attractive biomolecule in cancer treatment, a significant drawback of using the enterotoxin as an anticancer agent is its toxicity at the dose required for therapeutic efficacy. Furthermore, sufficient experimental evidence to justify the conclusion that SEB has therapeutic value in TG $\beta$ RI/II-positive cancer cells is yet to be demonstrated.

In conclusion, identification of molecular mechanisms involved in beneficial functions of biotoxins to treat cancer may provide a novel insight into immunotoxin-based cancer therapy; further investigation and development in these studies may add a further dimensions to cancer treatment. Nonetheless, the successful translation of these approaches into scientific practice is likely to depend on the outcome of clinical trials.

In the present study, SEB significantly reduced the expression of Smad2/3, which are components of the TGF- $\beta$ 
signaling pathway. It was further demonstrated that SEB may successfully suppress CRC proliferation, and that this suppression may be partially attributable to TGF- $\beta$ signaling pathway inhibition. The continued examination of these salient molecular features may yet facilitate the development of the effective immunotoxin-based therapy of malignancies.

\section{Acknowledgements}

The current study was supported by AJA University of Medical Sciences (Tehran, Iran).

\section{References}

1. Jemal, A, Bray, F, Center MM, Ferlay, J, Ward, E and Forman D: Global cancer statistics. CA Cancer J Clin 61: 69-90, 2011.

2. Carmona FJ and Esteller M: Epigenomics of human colon cancer. Mutat Res 693: 53-60, 2010.

3. Kim E, Coelho D and Blachier F: Review of the association between meat consumption and risk of colorectal cancer. Nutr Res 33: 983-994, 2013.

4. Mishra J, Drummond J, Quazi SH, Karanki SS, Shaw JJ, Chen B and Kumar N: Prospective of colon cancer treatments and scope for combinatorial approach to enhanced cancer cell apoptosis. Crit Rev Oncol Hematol 86: 232-250, 2013.

5. Mohan HM, O'Connor DB, O'Riordan JM and Winter DC: Prognostic significance of detection of microscopic peritoneal disease in colorectal cancer: A systematic review. Surg Oncol 22: e1-6, 2013.

6. Loh KW, Majid HA, Dahlui M, Roslani AC and Su TT: Sociodemographic predictors of recall and recognition of colorectal cancer symptoms and anticipated delay in help-seeking in a multiethnic asian population. Asian Pac J Cancer Prev 14: 3799-3804, 2013.

7. Ma J, Gao HM, Hua X, Lu ZY and Gao HC: Role of TGF- $\beta 1$ in human colorectal cancer and effects after cantharidinate intervention. Asian Pac J Cancer Prev 15: 4045-4048, 2014.

8. Bierie B and Moses HL: TGF- $\beta$ and cancer. Cytokine Growth Factor Rev 17: 29-40, 2006.

9. Jean-Jacques L: The dual role of TGF in human cancer: From tumor suppression to cancer metastasis. ISRN Mol Biol 7: 1-28, 2012.

10. Bierie B and Moses HL: TGFbeta: The molecular Jekyll and Hyde of cancer. Nat Rev Cancer 6: 506-520, 2006.

11. Ramasamy S, Nattarayan V, Jayaraj GG, Arulanandh MD and Jaiswal A: Bacterial infection-mediated anticancer activity (BIMAc) - revisiting the molecular mechanisms. J Med Hypoth Ideas 6: 19-22, 2012.

12. Nauts HC, Fowler GA and Bogatko FH. A review of the influence of bacterial infection and of bacterial products (Coley's toxins) on malignant tumors in man; a critical analysis of 30 inoperable cases treated by Coley's mixed toxins, in which diagnosis was confirmed by microscopic examination selected for special study. Acta Medica Scandinavica 276: 1-103, 1953.

13. Nauts HC: The beneficial effects of bacterial infections on host resistance to cancer: End result in 449 cases. Monograph no. 8. 2nd edition. Cancer Research Institute, New York, NY, USA, 1980.
14. Zacharski LR and Sukhatme VP: Coley's toxin revisited: Immunotherapy or plasminogen activator therapy of cancer? J Thromb Haemost 3: 424-427, 2005.

15. Hoption Cann SA, van Netten JP and van Netten C: Dr William Coley and tumour regression: A place in history or in the future. Postgrad Med J 79: 672-680, 2003.

16. Zhong L, Zhang X and Covasa M: Emerging roles of lactic acid bacteria in protection against colorectal cancer. World J Gastroenterol 20: 7878-7886, 2014.

17. Patyar S, Joshi R, Byrav DS, Prakash A, Medhi B and Das BK: Bacteria in cancer therapy: A novel experimental strategy. J Biomed Sci 17: 21-28, 2010.

18. Michl P, Buchholz M, Rolke M, Kunsch S, Löhr M, McClane B, Tsukita S, Leder G, Adler G and Gress T: Claudin-4: A new target for pancreatic cancer treatment using Clostridium perfringens enterotoxin. Gastroenterology 121: 678-684, 2001.

19. Kominsky SL, Vali M, Korz D, Gabig TG, Weitzman SA, Argani P and Sukumar S: Clostridium perfringens enterotoxin elicits rapid and specific cytolysis of breast carcinoma cells mediated through tight junction proteins claudin 3 and 4 . Am J Pathol 164: 1627-1633, 2004.

20. Gao Z and McClane BA: Use of Clostridium perfringens enterotoxin and the enterotoxin receptor-binding domain (C-CPE) for cancer treatment: Opportunities and challenges. J Toxicol 2012: 981626, 2012.

21. Ansiaux R and Gallez B: Use of botulinum toxins in cancer therapy. Expert Opin Investig Drugs 16: 209-218, 2007.

22. Mahmoodzadeh Hosseini H, Ali Imani Fooladi A, Soleimanirad J, Reza Nourani M and Mahdavi M: Exosome/staphylococcal enterotoxin B, an anti tumor compound against pancreatic cancer. J BUON 19: 440-448, 2014.

23. Hui J, Xiao F, Li H, Cui X, Liu H and Hu F: Inhibiting tumor-cell grow th by novel truncated staphylococcal enterotoxin $\mathrm{C} 2$ mutant. Sheng Wu Gong Cheng Xue Bao 27: 891-899, 2011.

24. Reis LO, Ferreira U, Billis A, Cagnon VH and Fávaro WJ: Anti-angiogenic effects of the superantigen staphylococcal enterotoxin B and bacillus Calmette-Guérin immunotherapy for nonmuscle invasive bladder cancer. J Urol 187: 438-445, 2012.

25. Dohlsten M, Hedlund G, Segren S, Lando PA, Herrmann T, Kelly AP and Kalland T: Human major histocompatibility complex class II-negative colon carcinoma cells present staphylococcal superantigens to cytotoxic T lymphocytes: Evidence for a novel enterotoxin receptor. Eur J Immunol 21: 1229-1233, 1991.

26. Fuller CL and Braciale VL: Selective induction of $\mathrm{CD}^{+}$ cytotoxic T lymphocyte effector function by Staphylococcus enterotoxin B. J Immunol 161: 5179-5186, 1998.

27. Ascenzi P, Visca P, Ippolito G, Spallarossa A, Bolognesi M and Montecucco C: Anthrax toxin: A tripartite lethal combination. FEBS Lett 531: 384-388, 2002.

28. Engedal N, Skotland T, Torgersen ML and Sandvig K: Shiga toxin and its use in targeted cancer therapy and imaging. Microb Biotechnol 4: 32-46, 2011.

29. Bandala C, Perez-Santos JL, Lara-Padilla E, Delgado Lopez G and Anaya-Ruiz M: Effect of botulinum toxin A on proliferation and apoptosis in the T47D breast cancer cell line. Asian Pac J Cancer Prev 14: 891-894, 2013.

30. Brigotti M, Arfilli V, Carnicelli D, Rocchi L, Calcabrini C, Ricci F, Pagliaro P, Tazzari PL, Alfieri RR, Petronini PG and Sestili P: Shiga toxin 1, as DNA repair inhibitor, synergistically potentiates the activity of the anticancer drug, mafosfamide, on raji cells. Toxins (Basel) 5: 431-444, 2013. 